Section Editor

John J. Millichap, MD

Education Research:

\title{
Neurology resident education
}

\section{Trending skills, confidence, and professional preparation}

Justin T. Jordan, MD

David Mayans, MD

Logan Schneider, MD

Nellie Adams, BA

Ayaz M. Khawaja, MD

John Engstrom, MD

Correspondence to

Dr. Jordan:

jtjordan@mgh.harvard.edu
Supplemental data at Neurology.org

\section{ABSTRACT}

Objective: To survey US-trained graduating neurology residents who are American Academy of Neurology members, in an effort to trend perceived quality and completeness of graduate neurology education.

Methods: An electronic survey was sent to all American Academy of Neurology members graduating from US neurology residency programs in the Spring of 2014

Results: Of 805 eligible respondents, 24\% completed the survey. Ninety-three percent of adult neurology residents and $56 \%$ of child neurology residents reported plans to pursue fellowship training after residency. Respondents reported a desire for additional training in neurocritical care, neuro-oncology, neuromuscular diseases, botulinum toxin injection, and nerve blocks. There remains a clear deficit in business training of neurology residents, although there was notable improvement in knowledge of coding and office management compared to previous surveys.

Discussion: Although there are still areas of perceived weakness in neurology training, graduating neurology residents feel generally well prepared for their chosen careers. However, most still pursue fellowship training for reasons that are little understood. In addition to certain subspecialties and procedures, practice management remains deficient in neurology training and is a point of future insecurity for most residents. Future curriculum changes should consider resident-reported gaps in knowledge, with careful consideration of improving business training. Neurology ${ }^{\circledR} 2016 ; 86$ :e112-e117

Graduate medical education is a constantly changing landscape built on the optimization of resident education, experience, and workload. In neurology, defining the best resident curriculum is challenged by a particularly rapid expansion of knowledge and shifting accreditation requirements. Among other tools for monitoring the state of neurology residency training in the United States, the American Academy of Neurology (AAN) surveys neurology residency program directors to evaluate national curriculum structure, effects of duty hour restrictions, and trends in recruitment and matching of residents. ${ }^{1-4}$ To understand trainee perceptions of neurology education, the AAN routinely surveys US-trained, AAN-member adult and child neurology residents. ${ }^{5,6}$ Previous resident surveys offered key insights into relative gaps in didactic curriculum, including basic neuroscience and business management, as well as resident perceptions of inadequate exposure to certain procedures and subspecialties.

Herein, we present the third survey of graduating AAN-member adult and child neurology residents in the United States, performed in an effort to longitudinally measure the structure and quality of graduate neurology education. In addition, delving further into previously noted deficiencies, much focus is given to procedural skills, diagnostic test interpretation, subspecialty exposure, practice preparation, and precise aspects of business training.

METHODS The survey instrument, presented in supplemental data on the Neurology ${ }^{\circledR}$ Web site at Neurology.org, was developed to explore resident-reported education experiences involving business training, procedural training, and various smaller constructs. The survey was designed with the help of the AAN's Consortium of Neurology Residents and Fellows and the AAN Member Insights Department and was approved by the AAN Graduate Education Subcommittee and Member Research Subcommittee.

The target audience included all AAN members doing primary neurology training in the United States with expected graduation dates in 2014, totaling 805 subjects. This included members classified as adult neurology residents, child neurology residents, or child

From the Pappas Center for Neuro-Oncology (J.T.J.), Massachusetts General Hospital, Boston; Neurology Consultants of Kansas (D.M.), Wichita; Department of Neurology (L.S.), Stanford University School of Medicine, CA; American Academy of Neurology Staff (N.A.), Minneapolis, MN; Department of Neurology (A.M.K.), University of Alabama Medical Center, Birmingham; and Department of Neurology (J.E.), University of California-San Francisco.

Go to Neurology.org for full disclosures. Funding information and disclosures deemed relevant by the authors, if any, are provided at the end of the article. 
neurology fellows (as such trainees are classified by certain institutions). Regardless of institutional nomenclature, all child neurology trainees are referred to as residents in this report. Members were e-mailed approximately 1 month before the expected graduation date by the chair of the Consortium of Neurology Residents and Fellows with a link to the online survey as well as information on a sweepstakes in which two $\$ 500$ gift cards would be raffled for incentive. Two additional reminder e-mails were sent to nonrespondents over the following 2 weeks. Data collection closed after 4 weeks.

A statistical comparison of responses from those who had completed adult neurology residencies $(n=168)$ and child neurology residencies $(n=27)$ was completed. Significant differences between groups are mentioned where relevant in this article. Overall survey analysis combined adult and child neurology residents. Comparisons between adult and child neurology respondents were tested for significance with $\chi^{2}$ tests, and longitudinal differences between survey responses, where relevant, were tested for significance with analysis of variance or $t$ tests.

RESULTS The survey response rate was $24.2 \%$ (195/805), which included 168 adult neurology residents and 27 child neurology residents. The margin of error for all respondents was $\pm 6.1 \%$ ( $95 \%$ confidence interval). Demographics of survey respondents are shown in table 1 . There were no differences between respondents and nonrespondents regarding age or sex.

Fellowship trends and subspecialty training. Eightyeight percent of respondents reported plans to pursue fellowship, $44 \%$ in their home institution and 56\% elsewhere. Broken down by residency type, significantly more adult neurology residents plan to pursue fellowship than child neurology residents $(93 \%$ vs $56 \%, p<0.0001)$. Subspecialties in which respondents ultimately plan to practice are shown in table 2 . When asked to mark all areas in which they plan to specialize, respondents most often selected general neurology (25\%), epilepsy (21\%), and vascular neurology (19\%). Forty-four percent of respondents selected multiple areas of specialization; when those individuals were then asked to identify a single

\begin{tabular}{llll} 
Table 1 & \multicolumn{2}{c}{ Demographic characteristics of the survey population } & \\
$\begin{array}{l}\text { Demographic } \\
\text { characteristics }\end{array}$ & $\begin{array}{l}\text { Survey } \\
\text { respondents }\end{array}$ & $\begin{array}{l}\text { Survey } \\
\text { nonrespondents }\end{array}$ & $\begin{array}{l}\text { Significance } \\
\text { testing, } \mathbf{p}\end{array}$ \\
$\begin{array}{l}\text { Age, y, mean (SD) } \\
\text { Sex, \% }\end{array}$ & $33.3(4.0)$ & $33.4(4.0)$ & 0.9 \\
$\quad$ Male & 51.6 & 55 & 0.45 \\
Female & 48.4 & 45 & \\
Neurology residency, \% & & & \\
Adult & 86.2 & & \\
Child & 13.8 &
\end{tabular}

There were no significant differences between age or sex among survey respondents and nonrespondents. Data were missing for age in $15 \%$ of respondents and $16 \%$ of nonrespondents. Data were missing for sex in $4 \%$ of respondents and $4 \%$ of nonrespondents.

\begin{tabular}{|c|c|c|}
\hline Table 2 & \multicolumn{2}{|c|}{$\begin{array}{l}\text { Planned subspecialty practice of } 192 \\
\text { residents graduating in } 2014\end{array}$} \\
\hline Subspeci & & $\%$ \\
\hline General n & ology & 24.5 \\
\hline Epilepsy & & 20.8 \\
\hline Vascular & urology & 18.8 \\
\hline Movemen & isorders & 14.1 \\
\hline Clinical $n$ & ophysiology & 14.1 \\
\hline Neurohos & alist & 11.5 \\
\hline Neurophy & $\log y$ & 10.9 \\
\hline Neurocrit & care & 9.9 \\
\hline Neuromus & lar medicine & 9.9 \\
\hline Child neu & gy & 9.4 \\
\hline Headache & edicine & 8.3 \\
\hline Neuro-on & ggy & 6.8 \\
\hline Neuroimn & ology and multiple sclerosis & 5.2 \\
\hline Behaviora & eurology & 4.7 \\
\hline Sleep me & & 3.6 \\
\hline Infectious & sease and neurovirology & 2.6 \\
\hline Traumatic & ain injury & 2.6 \\
\hline Neurogen & & 2.6 \\
\hline Endovasc & $r$ and interventional neurology & 2.1 \\
\hline Neuro-op & almology & 2.1 \\
\hline Neuroima & & 2.1 \\
\hline Neuromus & lar pathology & 2.1 \\
\hline Pain med & & 2.1 \\
\hline Autonomi & isorders & 1.6 \\
\hline Geriatric & urology & 1.6 \\
\hline Sports ne & logy & 1.6 \\
\hline Neuro-otc & & 1 \\
\hline Neuroepic & niology & 1 \\
\hline Palliative & urology & 0.5 \\
\hline Neural re & and rehabilitation & 0.5 \\
\hline Global he & & 0.5 \\
\hline Unsure & & 0.5 \\
\hline
\end{tabular}

Because of respondents choosing more than one response option, total percent sums to more than $100 \%$.

primary specialty, child and general neurology were most prevalent (both 13\%) followed by neurocritical care and vascular neurology (both 8\%). When asked the open-ended question of whether additional exposure to any topics could have better prepared respondents for their careers, neurocritical care, neuro-oncology, and neuromuscular disease were most frequently listed.

Procedure skills and diagnostic test interpretation. Extent of experience with various procedures is shown in table 3 . Of note, many respondents 
Table 3 Extent of resident experience with therapeutic or invasive neurologic procedures

\begin{tabular}{|llllll} 
Procedure & $\begin{array}{l}\text { Performed } \\
\text { more } \\
\text { than once }\end{array}$ & $\begin{array}{l}\text { Performed } \\
\text { once }\end{array}$ & $\begin{array}{l}\text { Observed } \\
\text { only }\end{array}$ & $\begin{array}{l}\text { No } \\
\text { training }\end{array}$ & $\begin{array}{l}\text { Not applicable } \\
\text { to residency }\end{array}$ \\
\hline Lumbar puncture & 97.9 & 1.1 & 0.5 & 0.5 & 0 \\
\hline IV tPA & 92.5 & 1.6 & 4.8 & 0.5 & 0.5 \\
\hline Botulinum toxin & 39.2 & 16.4 & 33.3 & 9.5 & 1.6 \\
\hline Local anti-inflammatory or anesthetic & 35.7 & 13.5 & 15.7 & 29.2 & 5.9 \\
\hline Nerve blocks & 28.5 & 9.7 & 23.1 & 32.8 & 5.9 \\
\hline VNS program & 22.7 & 11.9 & 36.8 & 25.9 & 2.7 \\
\hline DBS program & 11.2 & 8 & 49.5 & 25 & 6.4 \\
\hline IT pump management & 5.4 & 4.3 & 38.4 & 37.3 & 14.6 \\
\hline Muscle/nerve biopsy & 4.3 & 4.3 & 33.2 & 49.2 & 9.1 \\
\hline Lumbar drain placement & 3.2 & 5.4 & 24.2 & 48.9 & 18.3 \\
\hline IA thrombolysis & 1.1 & 0.5 & 64.2 & 21.9 & 12.3 \\
\hline Intravascular coiling & 1.1 & 0 & 46.7 & 34.4 & 17.8 \\
\hline Angioplasty and stenting & 0.5 & 1.6 & 51.9 & 25.1 & 20.9 \\
\hline Embolization & 0.5 & 0.5 & 43.2 & 36.2 & 19.5 \\
\hline
\end{tabular}

Abbreviations: DBS $=$ deep brain stimulator; IA $=$ intra-arterial; IT $=$ intrathecal; tPA $=$ tissue plasminogen activator; VNS $=$ vagus nerve stimulator.

Data are percentages. Number of respondents for each category is between 180 and 189 .

reported a desire for additional residency training in botulinum toxin injections (66\%), nerve blocks $(51 \%)$, vagus nerve stimulator programming $(33 \%)$, and deep brain stimulation programming (33\%). Adult neurology residents reported significantly more experience than child neurology residents in performing one or more instances of IV tissue plasminogen activator administration ( $98 \%$ vs $70 \%, p<0.0001)$. However, child neurology residents reported significantly more experience than adult neurology residents in performing one or more procedures of intrathecal pump management $(13 \%$ vs $9 \%, p<0.0001)$ and vagus nerve stimulator programming $(78 \%$ vs $28 \%$, $p<0.0001)$.

Resident-reported experience with interpreting diagnostic studies is summarized in table 4. The majority (88\%) of all respondents thought that they were either "very prepared" or "somewhat prepared" to perform the procedures that may be expected of them in their upcoming jobs or fellowships. Child neurology residents reported significantly less experience than adult neurology residents performing or interpreting EMG and nerve conduction studies (71\% vs $90 \%$, respectively, $p=0.04$ ).

Business training. Reported business training during residency is trended over time in the figure. While the majority of respondents thought that they were "not at all well" prepared or "not very well" prepared for competency in billing $(63 \%)$, coding $(63 \%)$, contract negotiations (80\%), office management $(80 \%)$, malpractice insurance $(84 \%)$, or relative value units $(79 \%)$, there were still significant improvements across serial surveys in preparation for coding $(p=$ $0.003)$ and office management $(p=0.01)$. Furthermore, between 2011 and 2014, there was a significant improvement in level of preparedness for billing $(p=$ $0.048)$.

Fifty-five percent of all respondents reported no business training during residency, 26\% reported informal, extracurricular training, and $19 \%$ reported business management training as a part of their residency curriculum. On the whole, $53 \%$ of respondents reported feeling either "very unprepared" or "somewhat unprepared" for practice management tasks that may be expected of them in their subsequent jobs, with only $6 \%$ feeling "very prepared" for these tasks. When asked what particular educational resources the AAN could develop to help residents and early-career members with business management, respondents' fill-in-the blank responses most commonly mentioned billing and coding.

Student loans. Graduating residents were asked about indebtedness from student loans and plans for repayment. These questions were optional, and only 22 responses were received. More than half of those who responded reported $>\$ 100,000$ in debt, with nearly one-third reporting $>\$ 200,000$. Almost one-third of respondents reported no specific plan for paying off their debt, while the others were equally split between fast and slow payoff plans. 


\begin{tabular}{|llllll|}
\hline Table 4 & Reported frequency of interpretation or performance of diagnostic studies & \\
Procedure & $\begin{array}{l}\text { Interpreted } \\
\text { more than once }\end{array}$ & $\begin{array}{l}\text { Interpreted } \\
\text { once }\end{array}$ & $\begin{array}{l}\text { Observed } \\
\text { interpretation }\end{array}$ & No training & $\begin{array}{l}\text { Not applicable } \\
\text { to training }\end{array}$ \\
\hline EEG & 96.8 & 0 & 3.2 & 0 & 0 \\
\hline MRI & 95.1 & 0.5 & 4.3 & 0 & 0 \\
\hline CT & 94 & 0 & 4.9 & 1.1 & 0 \\
\hline EMG/NCS & 86 & 1.6 & 12.4 & 0 & 0 \\
\hline Angiogram & 60.2 & 1.7 & 26.5 & 9.9 & 1.7 \\
\hline Evoked potentials & 31.7 & 9.8 & 31.7 & 26.2 & 0.5 \\
\hline PET & 25.7 & 8.2 & 37.2 & 24 & 4.9 \\
\hline TCD & 24.5 & 7.6 & 40.8 & 25 & 2.2 \\
\hline PSG & 21.9 & 11.5 & 41 & 24 & 1.6 \\
\hline Carotid US & 18.5 & 7.1 & 39.7 & 31 & 3.8 \\
\hline fMRI & 13.1 & 6 & 41.1 & 36.1 & 3.8 \\
\hline IOM & 9.9 & 4.9 & 42.3 & 39.6 & 3.3 \\
\hline Other & 1.7 & 1.7 & 10.3 & 41.4 & 44.8 \\
\hline
\end{tabular}

Abbreviations: $\mathrm{EMG} / \mathrm{NCS}$ = electromyography/nerve conduction study; $\mathrm{fMRI}=$ functional $\mathrm{MRI} ; \mathrm{IOM}=$ intraoperative monitoring; PSG = polysomnogram; TCD = transcranial Doppler; US = ultrasound.

Data are percentages. Number of responses for each category is between 181 and 186.

a SISCOM (subtraction ictal SPECT coregistered to MRI), DaT (dopamine transporter) scan, optical coherence tomography, video nystagmogram.

DISCUSSION While nearly $90 \%$ of graduating neurology residents believe they are prepared to perform the procedures necessary for their subsequent jobs, the rate of fellowship training remains high. Understanding

\section{Figure Graduating neurology resident preparation for business management topics}

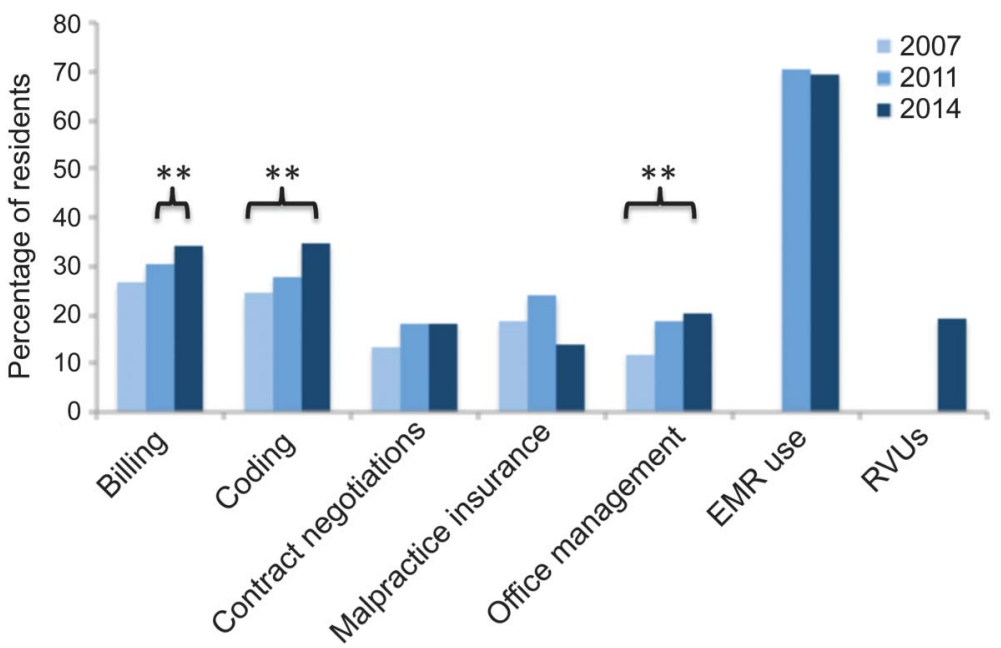

Percentage of 186 graduating residents feeling "very well" or "somewhat well" prepared for business management topics. These are compared to prior study results of neurology residents who graduated in 2007 and 2011, with similar "excellent" or "good" categorization. Questions on all 3 survey iterations were presented in a 4-point Likert scale design. Significant improvement was noted in the categories of coding $(p=0.003)$ and office management $(p=0.01$ ) when trended with 2007 and 2011, and in the category of billing preparedness when compared to 2011 ( $p=0.048$ ). The 2014 responses for meaningful use of electronic medical records were compared to 2011 responses for medical record use, because of category similarity. EMR = electronic medical record; RVUs = relative value units. the influences on this trend may provide important insight into the value and perceived needs of resident training, as well as the future of the neurology workforce. While education may be affected by systemic elements such as work hour restrictions and imbalance of inpatient and outpatient rotations, external factors such as board certification requirements and financial incentives likely impose equal pressure for trainees to seek fellowship training. Demonstrative of this, the American Board of Psychiatry and Neurology mandates 1 year of neurophysiology fellowship training to achieve eligibility for neurophysiology board certification. Not only is this certification prestigious but it also may be required as a condition of employment in various centers, and ultimately could even be required to bill for certain procedures. This latter point may be especially important for the $25 \%$ of respondents who will ultimately work in general neurology, of whom $81 \%$ reported plans for a fellowship first. Therefore, while curriculum changes may raise the bar for procedural exposure and competency, like the Neurology Milestones by the Neurology Residency Review Committee of the ACGME (Accreditation Council for Graduate Medical Education), ${ }^{7}$ their effect on postresidency training may be tempered by external incentives.

It is of interest that more than $50 \%$ of respondents reported a desire for more training on botulinum toxin injections and nerve blocks. This likely reflects the growing number of uses for these procedures, including in headache neurology, movement 
disorders, autonomic neurology, pain management, and rehabilitative neurology (both with and without Food and Drug Administration indications). Given that these are office-based procedures, and offer rapid therapeutic benefit to patients and potential revenue to practitioners, adding them to core competencies during residency training may be useful.

This survey revisited aspects of business management training important to residents' future careers. Although modest, there have been significant improvements in preparation for various business topics, including coding, billing, and office management, presumably reflecting increased exposure. The fact that more than two-thirds of respondents believe they are well trained for meaningful use of electronic medical records likely reflects not only the relatively young age and technologic savvy of respondents, but also focused hospital-required training. This was also the first AAN resident survey in which respondents were asked about competency in the use of relative value units, and less than $20 \%$ reported feeling either "very well" or "somewhat well" prepared to use these. While this number is quite low, it is in line with deficiencies in business training in general.

An important consideration in graduate medical education is trainee student loan indebtedness, and how this relates to training and career plans. The current survey provides the first look into this issue in graduating neurology residents. Although there were relatively few responses, the data nonetheless highlight the large amount of student debt held by graduating neurology residents and the lack of specific planning toward paying this off. This topic should be explored more thoroughly in future survey iterations, as well as how debt correlates with fellowship and career plans, and overall trainee and neurologist satisfaction.

The survey response rate of $24 \%$ was low compared to roughly $50 \%$ response rates in prior iterations of this survey. This reflects an ongoing trend toward lower response rates within all survey-based research through the AAN and may stem, in part, from survey fatigue. This was the first time the survey was incentivized with a drawing for two $\$ 500$ gift cards, which did not succeed in bringing response rates to 2007 or 2011 levels; future surveys may consider a small prize for each respondent rather than random drawings for large prizes. While the number of child neurology respondents was much smaller than adult neurology respondents ( $14 \%$ vs $86 \%$, respectively), this is reflective of the $12 \%$ of AAN members who self-describe as child neurology practitioners according to the 2015 AAN Member Insights Report, an unpublished report based on AAN member database information. However, the low absolute number of child neurology respondents limits the interpretability of population-specific data. It is worth noting, though, that the relative stability of various answers across serial surveys and the $6 \%$ margin of error on the present survey suggest that the results are nonetheless generalizable across AAN member graduating neurology resident cohorts.

The neurology resident survey will need to evolve as requirements and trends in education change. Possible future topics include the following: (1) develop an understanding of how student loan indebtedness influences financial, personal, and professional choices of residents after training; (2) understand the perceived need for trainees to obtain fellowship training if they plan to pursue a career in general neurology; and (3) determine whether residency training programs are providing instruction about reducing variance in the care of patients with similar neurologic problems within a practice or health system, in line with priorities designated by the Affordable Care Act and the Institute of Medicine Report on the Future of Graduate Medical Training in the United States. In addition, evaluating both specific fellowships pursued and subspecialty career plans may improve interpretation of the trends. Longitudinal follow-up of survey respondents may also be helpful in order to reevaluate perceived training deficiencies and strengths after entering neurology careers. The AAN performs qualitative studies of early-career neurologists, which serve to better capture the benefits and incentives for fellowship training. The data from these groups may provide additional insights into the preparation of future surveys.

\section{AUTHOR CONTRIBUTIONS}

Design of study: Jordan, Mayans, Schneider, Adams, Engstrom. Analysis and interpretation of data: Jordan, Mayans, Schneider, Adams, Khawaja. Drafting of the manuscript: Jordan, Adams. Critical revision of the manuscript for important intellectual content: Jordan, Mayans, Schneider, Adams, Khawaja, Engstrom.

\section{ACKNOWLEDGMENT}

The authors thank Cheryl Alementi, Lucy Persaud, the members of the AAN Graduate Education and Member Research Subcommittees and Consortium of Neurology Residents and Fellows, the AAN Member Insights Department, as well as all respondents of our survey.

\section{STUDY FUNDING}

No targeted funding reported.

\section{DISCLOSURE}

J. Jordan previously served as an officer of the American Academy of Neurology, Consortium of Neurology Residents and Fellows, and reports no financial disclosures. D. Mayans previously served as an officer of the American Academy of Neurology, Consortium of Neurology Residents and Fellows, and reports no financial disclosures. L. Schneider is an officer of the American Academy of Neurology, Consortium of Neurology Residents and Fellows, and reports no financial disclosures. N. Adams is an employee of the American Academy of Neurology. A. Khawaja is an officer of the American Academy of Neurology, Consortium of Neurology Residents and Fellows, and reports no financial disclosures. J. Engstrom is an officer of the American Academy of Neurology, and reports no financial disclosures. Go to Neurology.org for full disclosures.

\section{REFERENCES}

1. Adair JC, Rudnicki SA, Boudreau E, Weiner WJ, Coyle PK, Corboy JR. Survey of training programs' means 
for promoting neurology and attracting trainees. Neurology 2006;67:936-939.

2. Bradley WG. Neurology in the next two decades: report of the Workforce Task Force of the American Academy of Neurology. Neurology 2000;54:787-789.

3. Corboy JR, Boudreau E, Morgenlander JC, Rudnicki S, Coyle PK. Neurology residency training at the millennium. Neurology 2002;58:1454-1460.

4. Schuh LA, Adair JC, Drogan O, Kissela BM, Morgenlander JC, Corboy JR. Education research: neurology residency training in the new millennium. Neurology 2009;72:e15-e20.
5. Freeman WD, Nolte CM, Matthews BR, Coleman M, Corboy JR. Results of the American Academy of Neurology resident survey. Neurology 2011;76: e61-e67.

6. Johnson NE, Maas MB, Coleman M, Jozefowicz R, Engstrom J. Education research: neurology training reassessed. The 2011 American Academy of Neurology Resident Survey results. Neurology 2012;79:1831-1834.

7. Lewis SL, Jozefowicz RF, Kilgore S, Dhand A, Edgar L. Introducing the neurology milestones. J Grad Med Educ 2014;6(1 suppl 1):102-104. 


\section{Neurology}

\section{Education Research: Neurology resident education: Trending skills, confidence, and professional preparation}

Justin T. Jordan, David Mayans, Logan Schneider, et al. Neurology 2016;86; e112-e117

DOI 10.1212/WNL.0000000000002463

\section{This information is current as of March 14, 2016}

\section{Updated Information \& Services}

Supplementary Material

\section{References}

Citations

Subspecialty Collections

\section{Permissions \& Licensing}

Reprints including high resolution figures, can be found at: http://n.neurology.org/content/86/11/e112.full

Supplementary material can be found at: http://n.neurology.org/content/suppl/2016/03/12/WNL.0000000000002 463.DC1

This article cites 7 articles, 6 of which you can access for free at: http://n.neurology.org/content/86/11/e112.full\#ref-list-1

This article has been cited by 5 HighWire-hosted articles: http://n.neurology.org/content/86/11/e112.full\#\#otherarticles

This article, along with others on similar topics, appears in the following collection(s):

\section{All Education}

http://n.neurology.org/cgi/collection/all_education

Other Education

http://n.neurology.org/cgi/collection/other_education

Information about reproducing this article in parts (figures,tables) or in its entirety can be found online at:

http://www.neurology.org/about/about_the_journal\#permissions

Information about ordering reprints can be found online: http://n.neurology.org/subscribers/advertise

Neurology ${ }^{\circledR}$ is the official journal of the American Academy of Neurology. Published continuously since 1951, it is now a weekly with 48 issues per year. Copyright (O 2016 American Academy of Neurology. All rights reserved. Print ISSN: 0028-3878. Online ISSN: 1526-632X.

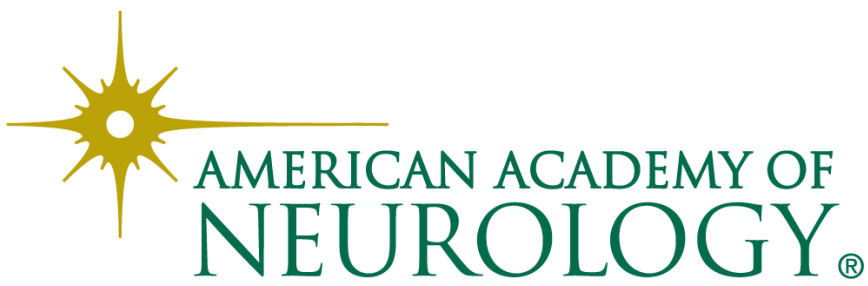

